ISSN 1420-3049

www.mdpi.com/journal/molecules

Article

\title{
Surface-enhanced Raman Spectral Measurements of 5-Fluorouracil in Saliva
}

\author{
Stuart Farquharson ${ }^{1, *}$, Alan Gift ${ }^{1}$, Chetan Shende ${ }^{1}$, Frank Inscore ${ }^{1}$, Beth Ordway ${ }^{2}$, \\ Carl Farquharson ${ }^{2}$ and John Murren ${ }^{2}$
}

1 Real-Time Analyzers, Inc., Middletown, CT 06457, USA

E-mails: Alan@rta.biz (A. G.), Chetan@rta.biz (C. S.), Inscore@rta.biz (F. I.)

2 Yale University, New Haven, CT 06520, USA

* Author to whom correspondence should be addressed; E-mail: stu@rta.biz; Tel. +1-860-635-9800; Fax: +1-860-635-9804.

Received: 8 August 2008; in revised form: 16 October 2008 / Accepted: 20 October 2008 / Published: 22 October 2008

\begin{abstract}
The ability of surface-enhanced Raman spectroscopy (SERS) to measure 5fluorouracil (5-FU) in saliva is presented. The approach is based on the capacity of Raman spectroscopy to provide a unique spectral signature for virtually every chemical, and the ability of SERS to provide $\mu \mathrm{g} / \mathrm{mL}$ sensitivity. A simple sampling method, that employed 1$\mathrm{mm}$ glass capillaries filled with silver-doped sol-gels, was developed to isolate 5-FU from potential interfering chemical components of saliva and simultaneously provide SERSactivity. The method involved treating a $1 \mathrm{~mL}$ saliva sample with $1 \mathrm{~mL}$ of acetic acid, drawing $10 \mu \mathrm{L}$ of sample into a SERS-active capillary by syringe, and then measuring the SER spectrum. Quality SER spectra were obtained for samples containing as little as $2 \mu \mathrm{g}$ of 5 -FU in $1 \mathrm{~mL}$ saliva. The entire process, the acid pretreatment, extraction and spectral measurement, took less than 5 minutes. The SERS of 5-fluorouridine and 5-fluoro-2'deoxyuridine, two major metabolites of 5-FU, were also measured and shown to have unique spectral peaks. These measurements suggest that disposable SERS-active capillaries could be used to measure 5-FU and metabolite concentrations in chemotherapy patient saliva, thereby providing metabolic data that would allow regulating dosage. Tentative vibrational mode assignments for 5-FU and its metabolites are also given.
\end{abstract}

Keywords: 5-FU; Chemotherapy; Drug analysis; Saliva analysis; Raman; SERS 


\section{Introduction}

5-Fluorouracil (5-FU) is often prescribed for solid tumors and colorectal carcinoma [1]. The success of 5-FU, like other chemotherapy drugs, is based on the higher replication rate of cancerous cells and corrupted biochemical synthesis, leading to cytosis. However, for most chemotherapy drugs these effects are not cancer cell specific, and normal cell growth throughout the body is also adversely affected. Furthermore, the body localizes or concentrates many of these drugs as they are processed by the liver and kidney resulting in damage to these organs. These dangerous side-effects preclude the use of traditional clinical trials involving numerous patients to establish statistical bases for dosages. Instead, initial dosage is based on the limited sets of previously treated patients, and the individual patient's body surface area. Recently, the latter has been shown to be ineffective [2]. Determining safe and effective dosage has been, and remains, a significant challenge.

The metabolism of 5-FU has been extensively studied and several well characterized biochemical pathways have been defined (Figure 1) [3-5]. In the anabolic pathway (cytotoxic mechanism) 5-FU is first converted to the nucleosides 5-fluorouridine (5-FUrd) and 5-fluoro-2'-deoxyuridine (5-FdUrd), and eventually to one of three active nucleotides: 5-fluorodeoxyuridine monophosphate (FdUMP), 5fluorodeoxyuridine triphosphate (FdUTP), or 5-fluorouridine triphosphate (FUTP). FUTP and FdUTP are incorporated into RNA and DNA, respectively, impairing gene-encoding and ultimately preventing cell growth, while FdUMP inhibits the enzyme thymidine synthase and subsequently preventing DNA synthesis. In the catabolic pathway, dihydropyrimidine dehydrogenase (DPD) metabolizes 5-FU to an inactive form, 5-fluoro-dihydrouracil $\left(5-\mathrm{FUH}_{2}\right)$. This is significant, in that there is a substantial genetic-based variation in the amount of DPD in individuals, and the amount of 5-FU metabolized can range from $15-80 \%$. Consequently, employing a "standard" dose of 5-FU based on body surface area has led to severe toxicity, and even death, in individuals deficient in DPD [6, 7].

Figure 1. The metabolism pathways of 5-fluorouracil in humans (modification of Ref. [5]). Abbreviations: 5-FU, 5-fluorouracil; 5- $\mathrm{FUH}_{2}$, 5-fluoro-5,6-dihydrouracil; 5-FUrd, 5fluorouridine; 5-FdUrd, 5-fluoro-2'-deoxyuridine; FUMP, 5-fluorouridine-5'monophosphate; FBAL, $\alpha$-fluoro- $\beta$-alanine.

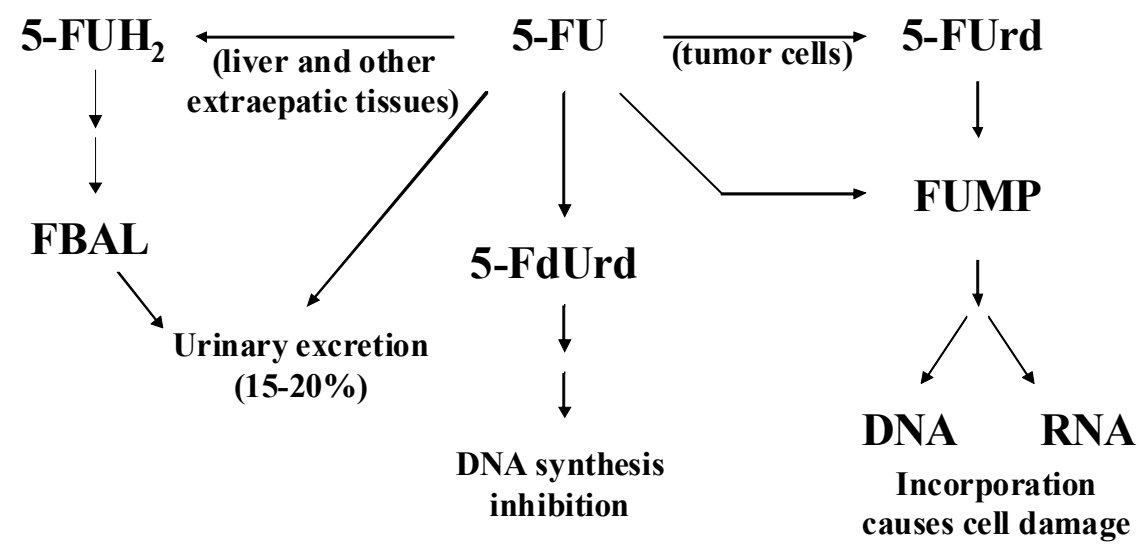

A more direct method of regulating drug dosage is to monitor drug metabolism while it is being administered. Unfortunately, the current methods used to measure drug metabolism are severely limited. These analytical methods employ multiple steps to isolate the parent drug and its metabolites 
from the numerous biochemicals and biological components in blood serum and urine. For urine, drug isolation usually employs: 1) an organic solvent to isolate the drugs and metabolites from natural components, 2) chromatography to separate the drugs, metabolites, chemicals and biochemicals (typically gas or high performance liquid chromatography) [8,9], with detection and quantification by an ultraviolet detector (non-chemical specific), or more definitively by a fluorescent spectrometer $[10,11]$ or mass spectrometer [12]. Inclusion of standards throughout this process is required to ensure measurement accuracy. Serum employs several additional steps, including centrifugation to remove red blood cells. These methods are labor intensive and time consuming (>hour). Furthermore, the large volumes of blood required (10 mL every 30 minutes) [13] could further jeopardize the patient's health due to a depleted blood supply. Consequently, monitoring metabolism is limited to an as needed basis [14].

Saliva analysis has long been considered a potential alternative to the approaches described above, and recent research has shown that drug metabolism is often equally represented in saliva as it is in blood plasma, typically at $\mu \mathrm{g} / \mathrm{mL}$ concentrations [15-18]. Analysis of saliva provides a highly desirable option, in that it is non-invasive, reduces the risk of HIV infection, is readily obtained, and is relatively easy to chemically analyze. Saliva is $99.5 \%$ water, and the concentrations of interfering physiological chemicals are typically 100 or more times less than in blood plasma or urine [19]. Current techniques for saliva analysis, however, like that of blood, require the use of 10 to $20 \mathrm{~mL}$ samples in order to enable chemical separation and detection of drugs and their metabolites, and such quantities are difficult for the patient to generate. A recent pharmacokinetic investigation has shown that 5-FU concentrations in saliva closely match those in plasma, reaching a maximum of 15-28 $\mu \mathrm{g} / \mathrm{mL}$ and a three hour minimum of $0.1 \mu \mathrm{g} / \mathrm{mL}$ (patient dependent) [18].

One approach that has been used to measure chemicals at $\mu \mathrm{g} / \mathrm{mL}$ concentrations is surfaceenhanced Raman spectroscopy (SERS). SERS has the potential to perform this analysis with just a few drops of sample due to its extreme sensitivity demonstrated by single molecule detection [20, 21]. In addition, the rich molecular vibrational information provided by Raman scattering yields exceptional selectivity and allows virtually any chemical to be identified, while also distinguishing multiple chemicals in mixtures $[22,23]$. Recently, SERS has been used to measure a wide range of different pharmaceuticals [24-26], as well as several chemotherapy drugs [27], including mitoxantrone [28-30], acridine drugs [31], and anthraquinone drugs [32].

5-FU has been given special attention in our work [33-36], since it is widely used, is well represented in saliva, and the metabolism of this drug varies enormously from individual-to-individual. Here we present the SERS analysis of 5-fluorouracil, 5-fluorouridine and 5-fluoro-2'-deoxyuridine. In the case of 5-FU, pH dependence and concentration studies are also provided, along with the development of a method to measure $2 \mu \mathrm{g}$ in $1 \mathrm{~mL}$ of saliva. These measurements provide the foundation for developing simple sampling devices, such as disposable SERS-active capillaries, to measure chemotherapy drugs and their metabolites at physiological concentrations in less than a drop of saliva within 5 minutes. Such a device would allow monitoring drug metabolism and regulating dosage during administration, and ultimately improving cancer patient outcome on an individual basis. 


\section{Results and Discussion}

Surface-enhanced Raman spectra of chemicals are often different from their normal Raman spectral counterparts. This is largely due to surface interactions that enhance various vibrational modes to different extents resulting in spectral peaks shifts and changes in relative intensity. For this reason, the normal Raman spectrum of 5-FU, 5-FUrd, and 5-FdUrd were also measured to aid interpretation of the SERS spectra.

The molecular structure of 5-FU is similar to uracil except for a fluorine substitution at the $\mathrm{C}_{5}$ position on the ring (Figure 2). Consequently, most of the Raman peaks can be assigned to modes based on previous analysis of uracil [37, 38]. Raman spectra of 5-FU have also been analyzed (Figure 3A), [39] recently with the aid of ab initio calculations [35, 40], and the contributions of fluorine to vibrational modes have been added. Combining these assignments, the dominant peaks in the Raman spectrum of 5-FU at 365, 410, 467, 544, 635, 766, 1223, 1347, 1423, 1653 and $1669 \mathrm{~cm}^{-1}$ are assigned to one out-of-plane pyrimidine ring bending mode, four in-plane ring bending modes, the ring breathing mode, the ring plus $\mathrm{C}-\mathrm{F}$ stretching mode, the ring plus $\mathrm{C}-\mathrm{H}$ wagging mode, the ring plus the two $\mathrm{N}-\mathrm{H}$ wagging modes, the $\mathrm{C}=\mathrm{C}$ stretching mode, and the symmetric $\mathrm{C}=\mathrm{O}$ stretching mode, respectively (Table 1). The addition of the fluorine atom, causes many peaks to shift, as expected, such as the ring breathing mode from $780 \mathrm{~cm}^{-1}$ for uracil to $766 \mathrm{~cm}^{-1}$ for 5-FU. This is consistent with theoretical calculations that predict a $32 \mathrm{~cm}^{-1}$ lower frequency shift for fluorine substitution. Albeit, the authors of a recent published Raman spectrum of 5-FU assign the $766 \mathrm{~cm}^{-1}$ peak to the out-of-plane $\mathrm{C}_{4}=\mathrm{O}$ carbonyl bend [40].

Figure 2. Chemical structure of A) 5-fluorouracil, B) 5-fluorouridine and C) 5-fluoro-2'deoxyuridine. Each atom of the ring for 5-FU is labeled 1 to 6 to define substitution position.

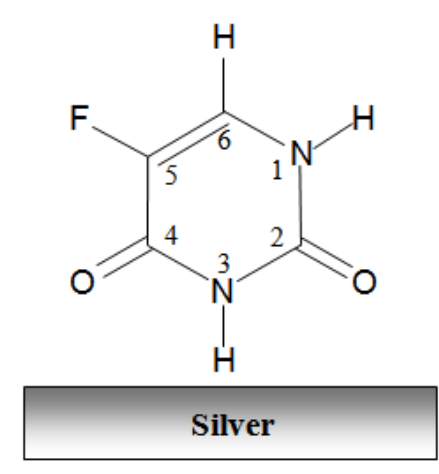

A

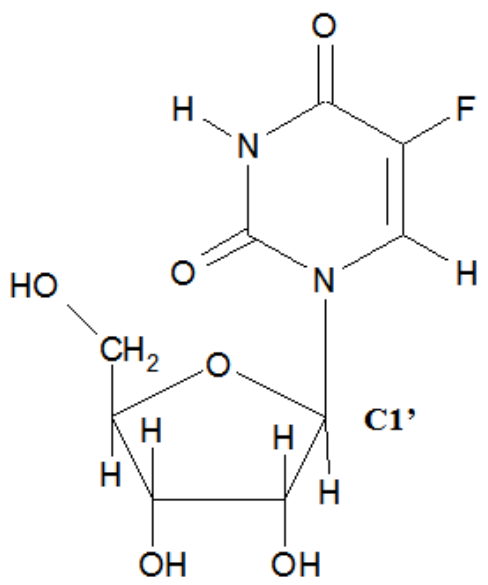

B

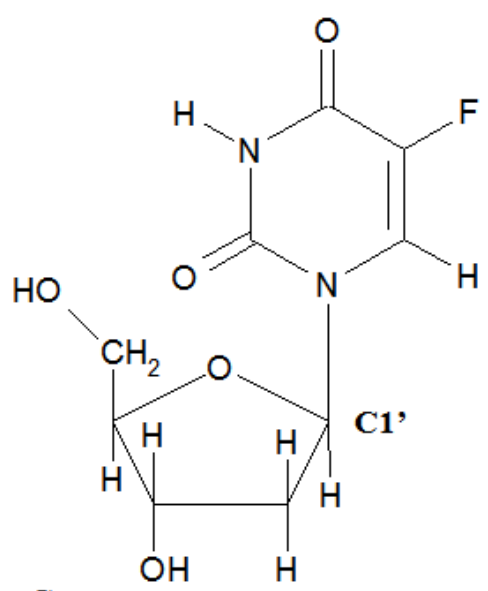

C 
Figure 3. A) Raman and B) SER spectra of 5-fluorouracil. Conditions: A) crystalline powder, $150 \mathrm{~mW}$ of $785 \mathrm{~nm}, 1 \mathrm{~min}, \mathrm{~B}) 1 \mathrm{mg} / \mathrm{mL}, 100 \mathrm{~mW}$ of $785 \mathrm{~nm}, 2 \mathrm{~min}$.

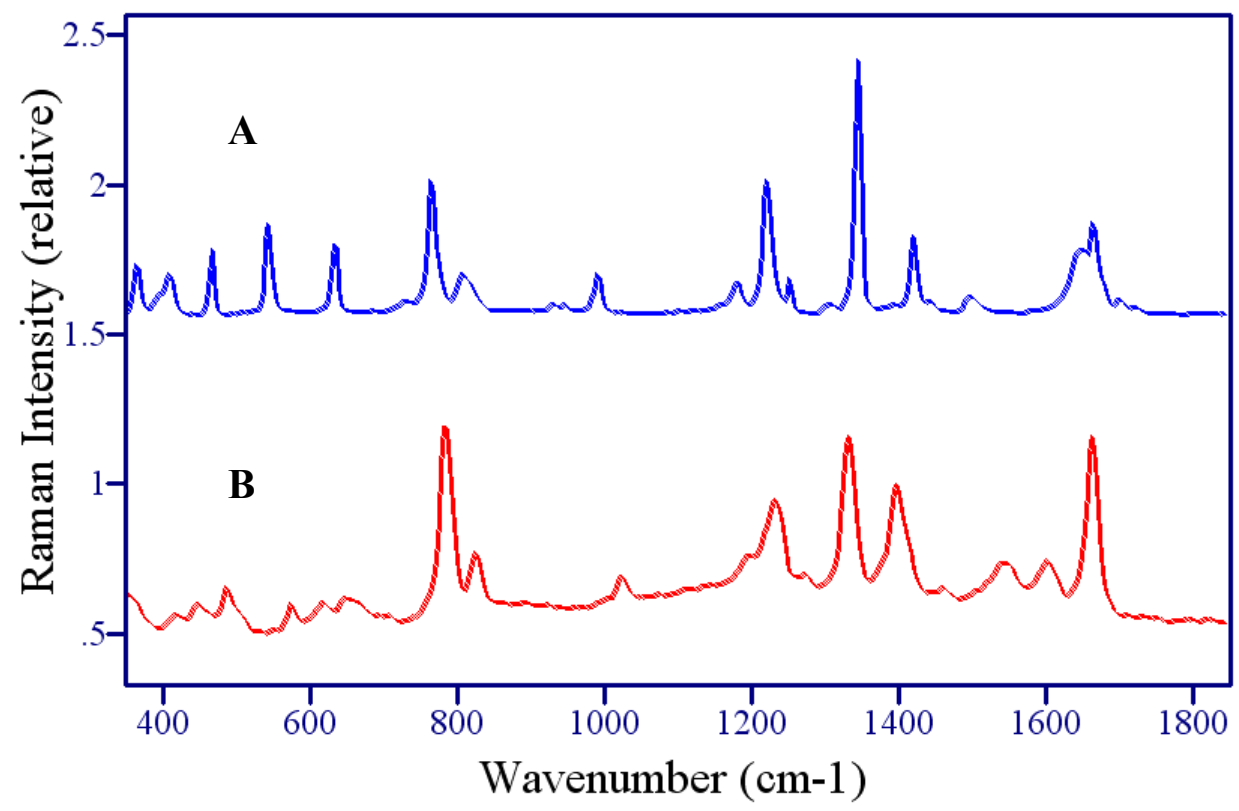

The surface-enhanced Raman spectrum of 5-FU is dominated by peaks at 786, 1234, 1334, 1400, and $1667 \mathrm{~cm}^{-1}$ (Figure 3B), and, based on peaks at similar frequency in the Raman, are assigned to the pyrimidine ring breathing mode, the trigonal ring plus $\mathrm{C}-\mathrm{F}$ stretching mode, a ring plus $\mathrm{C}-\mathrm{H}$ wagging mode, a ring plus $\mathrm{N}-\mathrm{H}$ wagging modes, and the symmetric $\mathrm{C}=\mathrm{O}$ stretching mode (Table 1). Several peaks also appear in the low frequency region $\left(400-650 \mathrm{~cm}^{-1}\right)$, which are assigned to ring-bending modes as a group. The shift in frequency compared to the Raman spectrum for most of these modes suggests strong interaction with the silver surface, which enhance various vibrational modes to different extents resulting in spectral peak shifts and changes in relative intensity. Three previous studies showed shifts of very similar amounts for corresponding modes in uracil [40-43], and in one case it was concluded that the interaction was through a deprotonated nitrogen [43], while another study, concluded that the interaction was through the N3 position (see below) [35]. The direction of the shifts also suggest an increase in bond strength for the ring breathing mode and the ring plus C-F stretching mode ( 766 to $786 \mathrm{~cm}^{-1}$ and 1223 to $1234 \mathrm{~cm}^{-1}$, respectively), and a decrease in bond strength for the ring plus $\mathrm{C}-\mathrm{H}$ and $\mathrm{N}-\mathrm{H}$ wagging modes (1347 to $1334 \mathrm{~cm}^{-1}$ and 1423 to $1400 \mathrm{~cm}^{-1}$, respectively).

In addition to these shifts in frequency, several peaks change relative intensity in the SERS spectrum compared to the Raman spectrum. In particular, the $786 \mathrm{~cm}^{-1}$ ring breathing mode and the $1667 \mathrm{~cm}^{-1} \mathrm{C}=\mathrm{O}$ stretching mode gain intensity, the $1653 \mathrm{~cm}^{-1} \mathrm{C}=\mathrm{C}$ stretch disappears, and new peaks appear at 1545 and $1606 \mathrm{~cm}^{-1}$. Together these changes are consistent with previous assertions for uracil, which state that the molecule is oriented to the surface end-on, based on the fact that modes perpendicular to the surface are most enhanced [43]. In this orientation the ring breathing mode is perpendicular to the surface, along with the trigonal ring breathing mode that now appears at 1606 $\mathrm{cm}^{-1}$. The same trigonal mode has been observed in the SER spectra of pyrazine at $1590 \mathrm{~cm}^{-1}$ [44], supporting this assignment. Furthermore, the $\mathrm{C}=\mathrm{C}$ stretch at $1565 \mathrm{~cm}^{-1}$ disappears, which would occur 
if this mode were parallel to the surface as in the case of an end-on orientation to the surface through $\mathrm{N} 3$. The disappearance of this mode in the SERS spectrum has also been reported for 6-aminouracil [42]. The low frequency peaks (400-650 $\mathrm{cm}^{-1}$ ) all lose intensity as might be expected for ring bending modes, which vibrate more parallel than perpendicular to the surface.

It is clear from Figure 1, that it is highly desirable to not only measure 5-FU, but also 5-FUH ${ }_{2}$, FBAL, 5-FUrd, 5-FdUrd, and FUMP and show that their SER spectra are different so that concentrations can be determined. Furthermore, if these chemicals can be measured in the same saliva sample, the need to determine absolute concentrations will be minimized, since relative concentrations can be used to determine pharmacokinetics. Unfortunately, only 5-FUrd and 5-FdUrd were available at the time of this study. Since the concentration of $5-\mathrm{FUH}_{2}$ in saliva has added importance in that its ratio to 5-FU would indicate a patient's DPD level, it is worth noting that the SER spectra of the analogs uracil and dihydrouracil are substantially different. In particular, the pyrimidine ring breathing mode at $805 \mathrm{~cm}^{-1}$ for uracil shifts to $725 \mathrm{~cm}^{-1}$ for dihydrouracil [45].

5-Fluorouridine and 5-fluoro-2'-deoxyuridine differ in structure by the addition of D-ribose and Ddeoxyribose moieties at the $\mathrm{N}_{1}$ position of the uracil ring, respectively (Figure 2). Although the chemical structures for these two metabolites are extremely similar, the Raman spectra of the crystalline powders are surprisingly different (Figures 4 and 5), presumably due to a combination of intra- and inter-molecular forces. For the former, rotation about $\mathrm{N}_{1}$ and $\mathrm{C}_{1}$, and puckering of the ribose moiety can influence vibrations, and for the latter, hydrogen bonding and the local crystal environment can influence vibrations [46].

A comparison of the normal Raman and SERS spectra for 5-FUrd, crystalline powder and $1 \mathrm{mg} / \mathrm{mL}$ solution, respectively, is shown in Figure 4. The frequencies of the peaks are listed in Table 1. The normal Raman spectrum has many of the same features as 5-FU with peaks at 767, 1233, 1334, 1664 and $1695 \mathrm{~cm}^{-1}$ corresponding to the pyrimidine ring breathing mode, the ring plus $\mathrm{C}-\mathrm{F}$ stretch, the ring plus $\mathrm{C}-\mathrm{H}$ wag, the $\mathrm{C}=\mathrm{C}$ stretch, and the symmetric combination of the two $\mathrm{C}=\mathrm{O}$ stretches, respectively. The intensity of the normal Raman spectrum is significantly less in comparison to the 5-FU spectrum, especially for the ring modes. This is due mainly to the reduction in symmetry of the molecule with the addition of the ribose. Other peaks in the Raman spectrum appear at $492 \mathrm{~cm}^{-1}$, a group between 800 to $900 \mathrm{~cm}^{-1}$, and an intense peak at $1216 \mathrm{~cm}^{-1}$. These peaks are all assigned to combination modes of the uracil ring plus ribose vibrations.

The SERS spectrum of 5-FUrd is dominated by peaks at 794, 859, 1236, 1339, 1388 and $1661 \mathrm{~cm}^{-1}$, which are assigned to the pyrimidine ring breathing mode, the trigonal ring plus $\mathrm{C}-\mathrm{F}$ stretch, the ring plus $\mathrm{C}-\mathrm{F}$ stretch, the ring plus $\mathrm{C}-\mathrm{H}$ wag, the ring plus $\mathrm{N}-\mathrm{H}$ wag, and the $\mathrm{C}=\mathrm{O}$ symmetric stretch, respectively. As with 5-FU, the ring containing vibrational modes are enhanced the most indicating a surface adsorption interaction through the $\mathrm{N}_{3}$ with an upright geometry. Furthermore, the ribose modes do not appear to be enhanced, suggesting that this part of the molecule is directed away from the surface, which again supports an $\mathrm{N}_{3}$ surface interaction.

A comparison of the normal Raman and SERS spectra for 5-FdUrd, crystalline powder and 1 $\mathrm{mg} / \mathrm{mL}$ solution, respectively, are shown in Figure 5. Again, the frequencies of the peaks are listed in Table 1. The uracil ring vibrations in the normal Raman spectrum have lost intensity with respect to 5$\mathrm{FU}$, due to the reduction in symmetry, while the ribose containing modes have gained intensity compared to 5-FUrd. The peaks associated with the uracil ring at 764, 1225, 1355, $1685 \mathrm{~cm}^{-1}$ and the 
shoulder at $1713 \mathrm{~cm}^{-1}$ are assigned to the pyrimidine ring breathing mode, the ring plus $\mathrm{C}-\mathrm{F}$ stretch, the ring plus $\mathrm{C}-\mathrm{H}$ wag, the $\mathrm{C}=\mathrm{C}$ stretch, and the symmetric $\mathrm{C}=\mathrm{O}$ stretches, respectively. Other intense peaks at 496,687, 860,925, and $1199 \mathrm{~cm}^{-1}$ are all associated with combination modes containing both uracil ring and ribose vibrations.

Figure 4. A) Raman and B) SERS spectra of 5-fluorouridine. Conditions: A) crystalline powder, $100 \mathrm{~mW}$ of $785 \mathrm{~nm}, 5 \mathrm{~min}, \mathrm{~B}) 1 \mathrm{mg} / \mathrm{mL}, 100 \mathrm{~mW}$ of $785 \mathrm{~nm}, 3 \mathrm{~min}$.

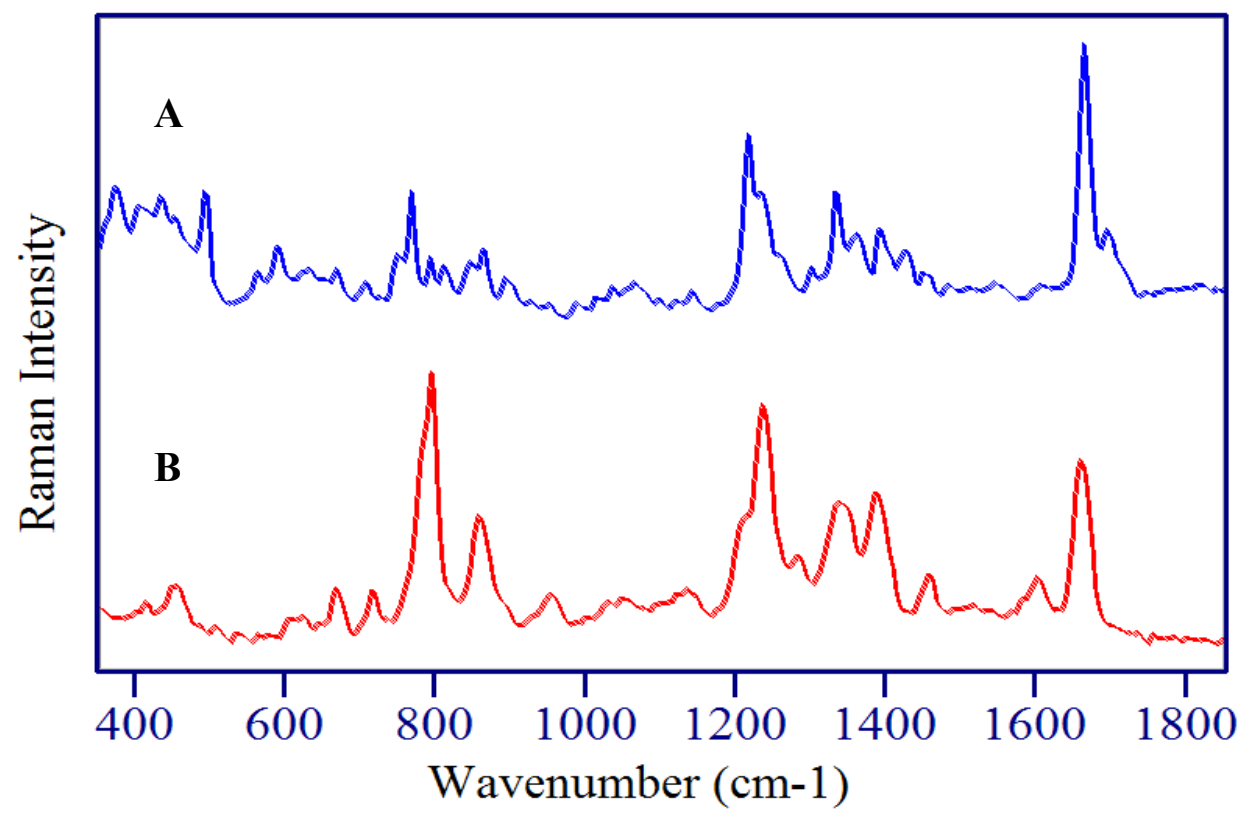

Figure 5. A) Raman and B) SER spectra of 5-fluoro-2'-deoxyruidine. Conditions: A) crystalline powder, $100 \mathrm{~mW}$ of $785 \mathrm{~nm}, 5 \mathrm{~min}, \mathrm{~B}) 1 \mathrm{mg} / \mathrm{mL}, 100 \mathrm{~mW}$ of $785 \mathrm{~nm}, 3 \mathrm{~min}$.

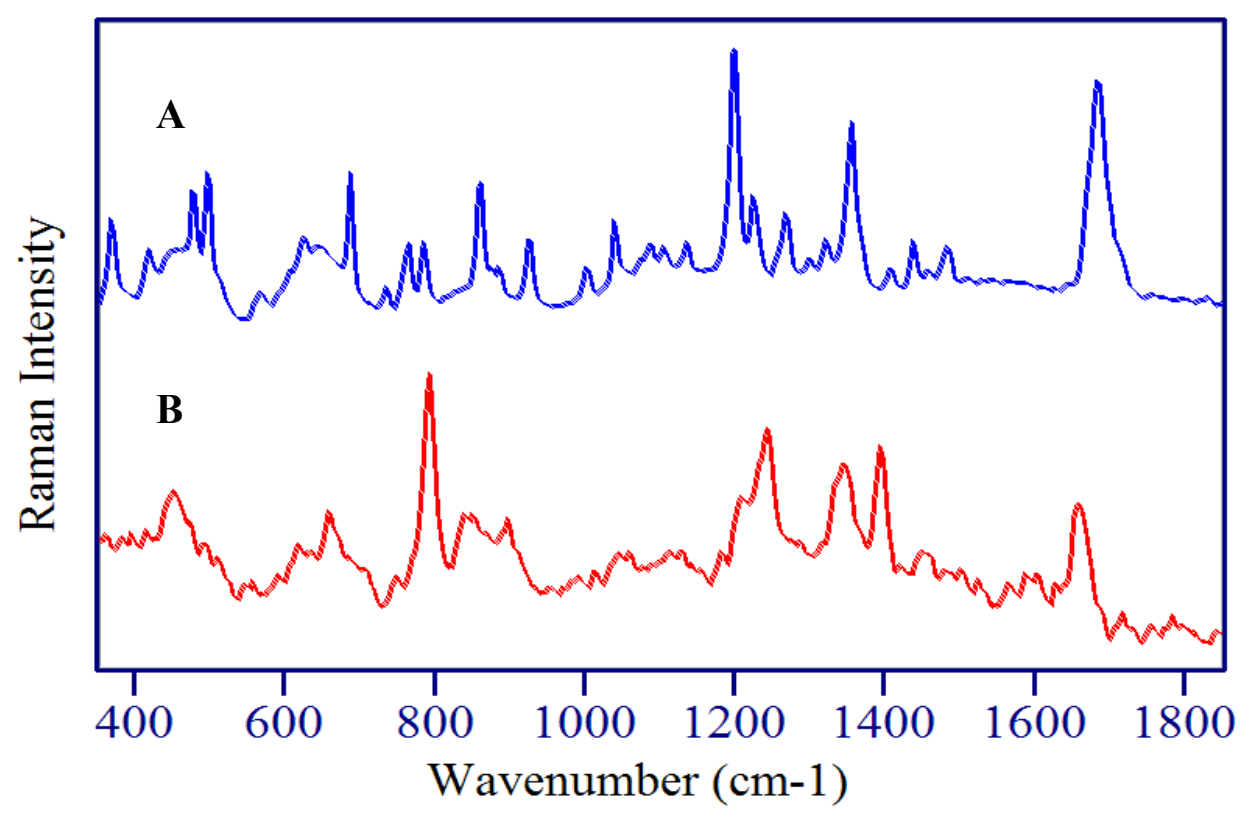


Table 1. Tentative vibrational mode assignments for the normal Raman (NR) and SERS peaks for 5-fluorouracil (5-FU) and its metabolites 5-fluorouridine (5-FUrd), and 5-fluoro 2 'deoxyuridine (5-FdUrd).

\begin{tabular}{|c|c|c|c|c|c|c|}
\hline \multicolumn{2}{|c|}{ 5-FU } & \multicolumn{2}{|c|}{ 5-FUrd } & \multicolumn{2}{|c|}{ 5-FdUrd } & \multirow[t]{2}{*}{ Tentative Assignments* } \\
\hline $\begin{array}{l}\mathrm{NR} \\
\left(\mathrm{cm}^{-1}\right)\end{array}$ & $\begin{array}{l}\text { SERS } \\
\left(\mathrm{cm}^{-1}\right)\end{array}$ & $\begin{array}{l}\mathrm{NR} \\
\left(\mathrm{cm}^{-1}\right)\end{array}$ & $\begin{array}{l}\text { SERS } \\
\left(\mathrm{cm}^{-1}\right)\end{array}$ & $\begin{array}{l}\mathrm{NR} \\
\left(\mathrm{cm}^{-1}\right)\end{array}$ & $\begin{array}{l}\text { SERS } \\
\left(\mathrm{cm}^{-1}\right)\end{array}$ & \\
\hline 365 & & 373 & & 369 & & Out-of-plane ring bend \\
\hline 410 & & & & 418 & & In-plane ring bend \\
\hline 467 & 488 & & 455 & 478 & 452 & In-plane ring bend \\
\hline 544 & & 492 & & 496 & & $\begin{array}{l}\text { In-plane ring bend + ribose } \\
\text { In-plane ring bend }\end{array}$ \\
\hline & & & & 567 & & Out-of-plane ring and $\mathrm{C}=\mathrm{O}$ bend \\
\hline 635 & & & $\begin{array}{l}667 \\
717\end{array}$ & 687 & 658 & $\begin{array}{l}\text { In-plane ring bend } \\
\text { Ring + ribose } \\
\text { Ring + ribose }\end{array}$ \\
\hline 732 & & 750 & & & & $\mathrm{~N}-\mathrm{H}$ out-of-plane bend \\
\hline 766 & 786 & 767 & 794 & 764 & 791 & Pyrimidine ring breathing \\
\hline 809 & 827 & 793 & 859 & 784 & 840 & Trigonal ring $+\mathrm{C}-\mathrm{F}$ \\
\hline & & 846 & & 860 & 896 & Ring + ribose \\
\hline & & 892 & & 925 & & Ring + ribose \\
\hline 933 & & & & & & Out-of-plane C6-H wag \\
\hline 947 & & & & & & In-plane C6-H wag \\
\hline & & & 954 & & & Ring + ribose \\
\hline & & & & 1002 & & Ring + ribose \\
\hline 994 & 1026 & & & & & Ring + N-H wag + C-H wag \\
\hline 1183 & 1199 & & & & & $\mathrm{~N} 3-\mathrm{H}$ in-plane bend \\
\hline & & 1216 & 1205 & 1199 & 1209 & Ring + ribose \\
\hline 1223 & 1234 & 1233 & 1236 & 1225 & 1242 & Ring + C-F \\
\hline 1255 & 1275 & & & 1268 & & Ring str. \\
\hline 1347 & 1334 & 1334 & 1339 & 1355 & 1345 & Ring + C-H wag \\
\hline 1423 & 1400 & & 1388 & & 1395 & Ring + N-H wags \\
\hline & & & 1457 & & 1450 & Ring str. + ribose $\mathrm{CH}_{2}$ \\
\hline 1502 & & & & & & $\mathrm{~N} 1-\mathrm{H}$ in-plane bend \\
\hline & 1545 & & & & & C6-H deformation \\
\hline & 1606 & & 1602 & & & Trigonal ring mode \\
\hline 1653 & & 1664 & & 1685 & & Ring $C=C$ str. \\
\hline 1669 & 1667 & 1695 & 1661 & 1713 & 1658 & Symmetric $\mathrm{C}=\mathrm{O}$ str. \\
\hline 1704 & & & & & & Anti-symmetric $\mathrm{C}=\mathrm{O}$ str. \\
\hline 1723 & & & & & & Fermi Resonance \\
\hline
\end{tabular}

*Vibrational mode assignments are based on references [36-40, 44], and this work.

The SERS spectrum of 5-FdUrd is again dominated by the uracil ring vibrational modes. The peaks at $791,840,1242,1345,1395$, and $1658 \mathrm{~cm}^{-1}$ are assigned to the pyrimidine ring breathing mode, the trigonal ring plus $\mathrm{C}-\mathrm{F}$ stretch, the ring plus $\mathrm{C}-\mathrm{F}$ stretch, the ring plus $\mathrm{C}-\mathrm{H}$ wag, the ring plus $\mathrm{N}-\mathrm{H}$ wag, and the symmetric $\mathrm{C}=\mathrm{O}$ stretches, respectively. There is also an additional feature at $896 \mathrm{~cm}^{-1}$ that represents a combination mode containing ring and ribose vibrational character. The appearance of this mode may be due to a different intramolecular orientation between the uracil and ribose moieties compared to 5-FUrd. In spite of the increased ribose features in the SERS spectrum, the uracil ring mode still dominates, and clearly establishes that this metabolite also interacts through the $\mathrm{N}_{3}$ in an end-on geometry. 
As stated previously, the SERS spectra for these three species are similar with many of the same vibrational modes being enhanced. Nevertheless, there are unique spectral features that can be used to identify each component. For example, Figure 6 shows that the 827 and $1026 \mathrm{~cm}^{-1}$ peaks are unique to 5-FU, the 716 and $954 \mathrm{~cm}^{-1}$ peaks are unique to 5-FUrd, and the $896 \mathrm{~cm}^{-1}$ peak is unique to 5-FdUrd. It therefore seems likely that simple spectral analysis could be used to identify and quantify each of these three species in a mixture. In the event that this approach is insufficient, chemometric-based software programs are available, which use the entire spectrum to identify and quantify multiple components in mixtures.

Figure 6. SERS spectra of A) 5-fluoro-2'-deoxyruidine, B) 5-fluorouridine, and C) 5fluorouracil. Unique peaks identified by *. Conditions as in Figures 3-5.

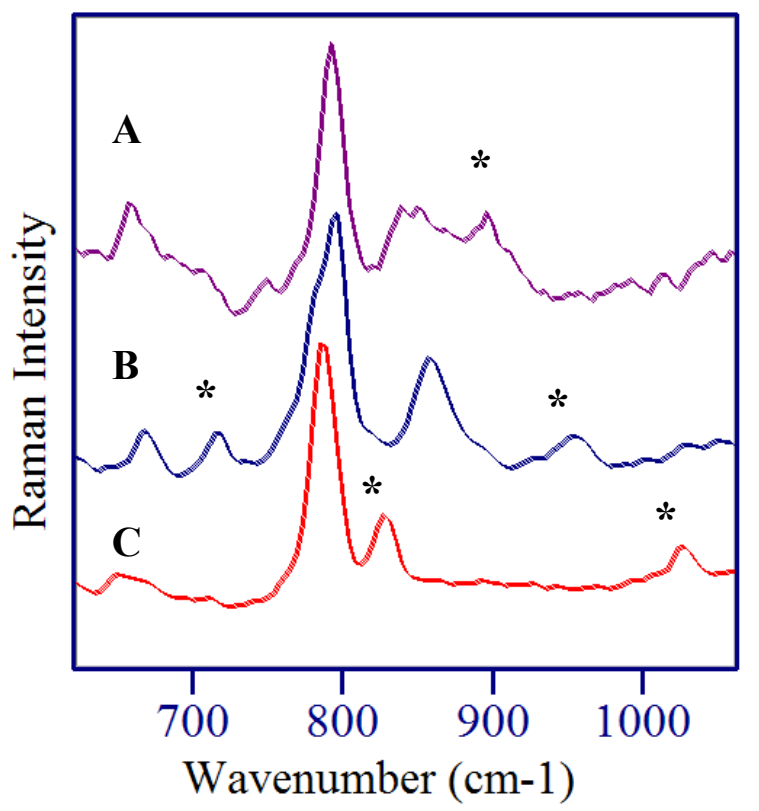

5-FU is a weak acid with a pKa of 7.93 [47], and consequently, depending on the ionic form, the $\mathrm{pH}$ can also strongly influence the molecule to surface interaction [48]. The $\mathrm{pH}$ dependence of the SERS spectrum is essential if quantitative measurements are to be made. Figure 7 shows the SERS spectra of 5-FU for selected $\mathrm{pH}$ values of 4.3, 5.6, 6.5, 9.2, and 10.7. The peaks at 1234,1400 and $1667 \mathrm{~cm}^{-1}$ decrease in intensity, while the peaks at 786 and $1335 \mathrm{~cm}^{-1}$ remain constant as the $\mathrm{pH}$ is made basic. Yet, the latter two peaks both shift in frequency towards each other by some $8 \mathrm{~cm}^{-1}$ as the $\mathrm{pH}$ is changed from 3.3 to 10.7. Although, this shift appears to trend the $\mathrm{pH}$, it is equivalent to the spectral resolution of the measurements and was not further analyzed. In addition, two new peaks appear at 1545 and $1606 \mathrm{~cm}^{-1}$. The decrease in the intensities of the 1234,1400 and $1667 \mathrm{~cm}^{-1}$ peaks are a consequence of the anion being formed. Deprotonation occurs at the $\mathrm{N}_{3}$ position [47], which essentially removes this interaction with the chloride anions on the silver surface, as well as that of the nearby carbonyl groups. It also appears that the intensity of the $1400 \mathrm{~cm}^{-1}$ ring plus N-H wagging mode is reduced by approximately $50 \%$, consistent with deprotonation and elimination of one of the two modes. The appearance of the peak at $1545 \mathrm{~cm}^{-1}$, assigned to the $\mathrm{C}_{6}-\mathrm{H}$ deformation mode, suggests that this part of the molecule now interacts with the chloride anion coated surface. The 1606 
$\mathrm{cm}^{-1}$ peak is tentatively assigned to a trigonal ring mode, based on the same mode observed in the SERS spectra of pyrazine at $1590 \mathrm{~cm}^{-1}$ [44], and the fact that formation of the anion leads to a high degree of $\pi$-electron delocalization [47].

Figure 7. A) Surface-enhanced Raman spectra of $1 \mathrm{mg} / \mathrm{mL} 5-\mathrm{FU}$ in water at $\mathrm{pH} \mathrm{A)} \mathrm{10.7,}$ B) 9.2 , C) 6.5 , D) 5.6, and E) 4.3. Conditions: $100 \mathrm{~mW}$ of $785 \mathrm{~nm}, 2 \mathrm{~min}$.

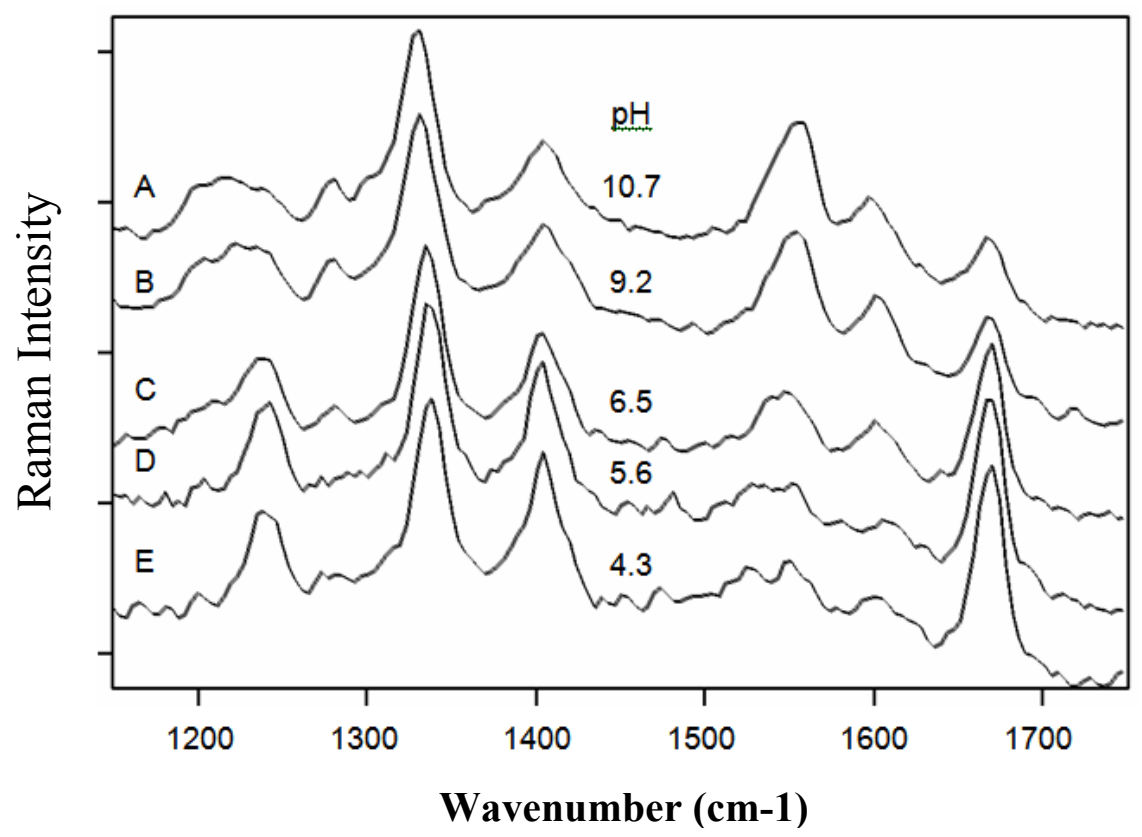

The intensities of the 1545 and $1667 \mathrm{~cm}^{-1}$ peaks, normalized to the $1335 \mathrm{~cm}^{-1}$ peak intensity, are plotted in Figure 8 as a function of $\mathrm{pH}$ and compared to the calculated concentration of the neutral and anionic forms based on the $\mathrm{pKa}$.

Figure 8. Plot of the $1545(\bullet)$ and $1667 \mathrm{~cm}^{-1}(\diamond)$ peak intensities (heights normalized to the $1335 \mathrm{~cm}^{-1}$ peak height) as a function of $\mathrm{pH}$ representing 5-FU' $\mathrm{FU}^{-}$a-FU, respectively. Lines represent predicted relative concentrations based on the $\mathrm{pKa}$ of 7.93 .

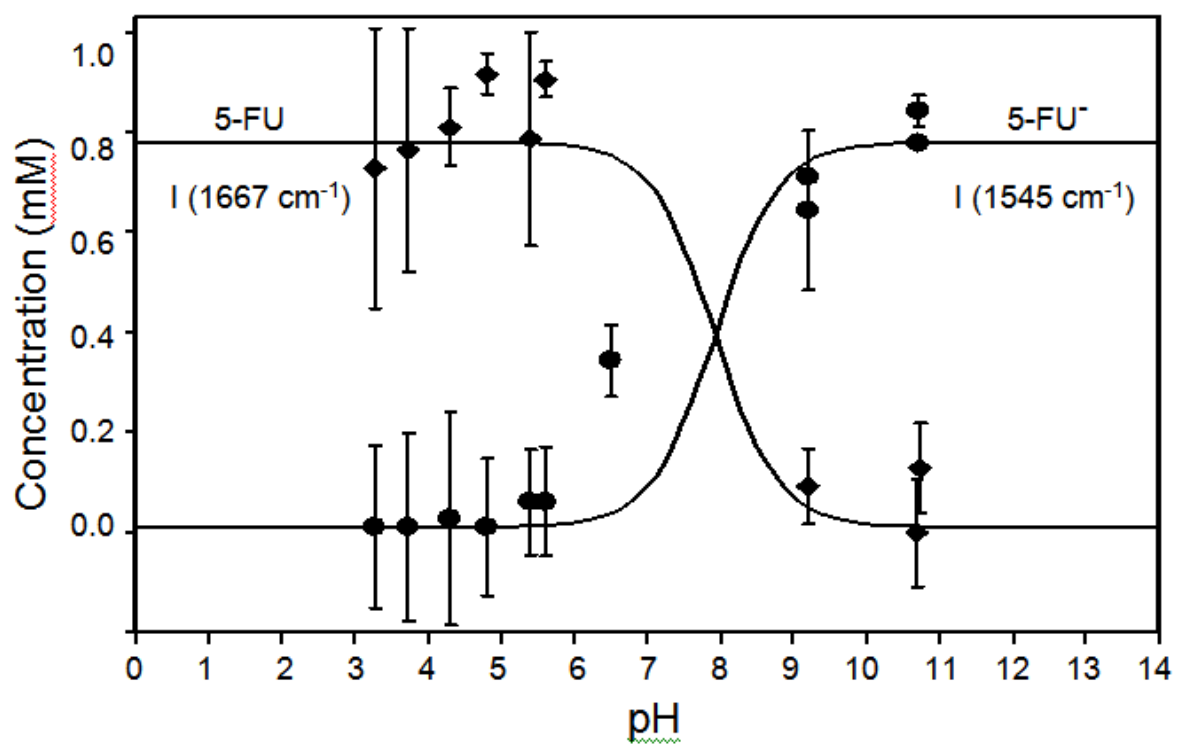


The decrease in the latter peak and increase in the former peak coincident with the pKa supports their respective assignment to the neutral and anionic forms. It is important to note that the 786 and $1335 \mathrm{~cm}^{-1}$ peak intensities are nearly constant as a function of $\mathrm{pH}$ and can therefore be used for quantitative analysis. Next, the ability of SERS to detect 5-FU at relevant concentrations was examined by measuring samples at decreasing concentrations. Specifically, samples of 500, 100, 10, 5, $1,0.5,0.1$, and $0.01 \mu \mathrm{g} / \mathrm{mL}$ were prepared and measured in the SERS-active capillaries (Figure 9A). At the lowest concentrations, a luminescent background becomes prominent, which is due to the metal impurities in the glass capillaries. This can be subtracted to reveal the 5-FU peaks (Figure 9B). The SERS intensity, measured as the $785 \mathrm{~cm}^{-1}$ peak area, as a function of concentration follows a Langmuir-Blodgett response, since it is a function of available silver surface area (Figure 10).

Figure 9. SER spectra of 5-FU at A) 500, 100, 10, 5, 1, 0.5, 0.1, $0.01 \mu \mathrm{g} / \mathrm{mL}$ (top to bottom) and B) $10 \mathrm{ng} / \mathrm{mL}$ 5-FU before (top) and after (bottom) subtraction of glass capillary background spectrum (middle). Conditions: silver-doped sol-gels in capillaries, $100 \mathrm{~mW}$ of $785 \mathrm{~nm}, 3-\mathrm{min}$.

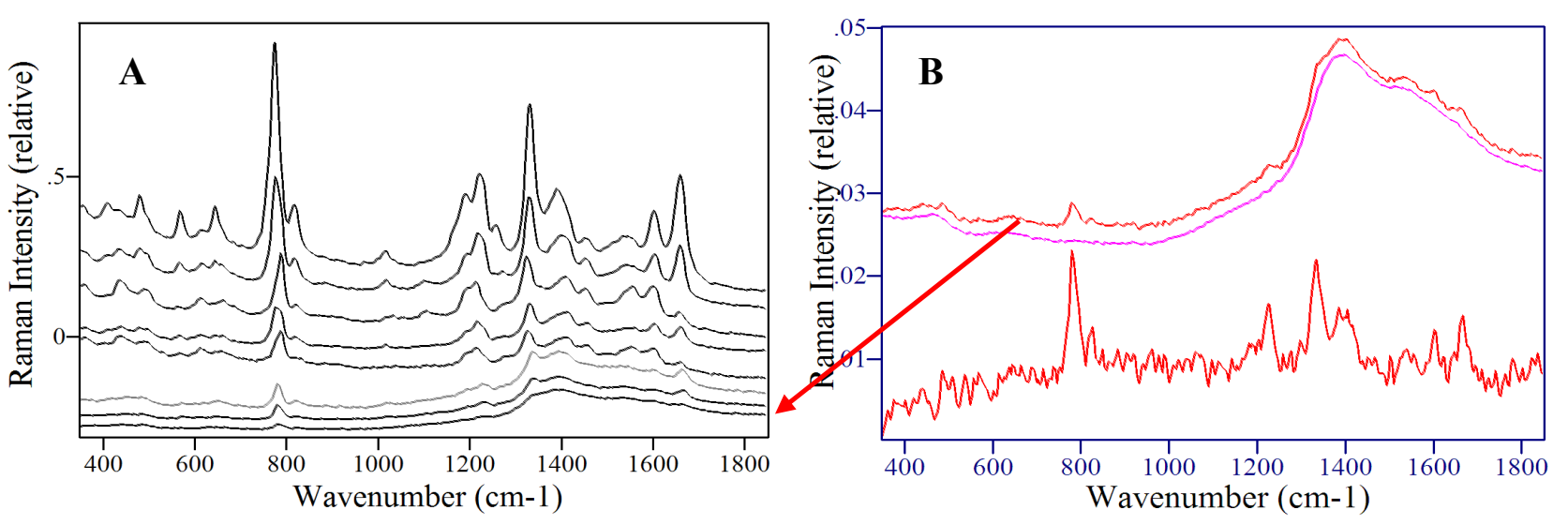

The first sample of 5-FU in saliva employed a relatively high concentration at $1 \mathrm{mg} / 1 \mathrm{~mL}$. The 5FU was artificially added to saliva and then drawn into SERS-active capillaries and measured. Although the 5-FU peaks are discernable, the spectrum is dominated by two additional peaks at 445 and $2095 \mathrm{~cm}^{-1}$ (Figure 11A). These peak frequencies match those previously reported for thiocyanate measured on a silver electrode [49]. This assignment was confirmed by preparing a $1 \mathrm{mg} / \mathrm{mL}$ thiocyanate sample and comparing it to the original saliva sample without 5-FU (Figure 12). Thiocyanate is physiologically extracted from some vegetables (e.g. broccoli) and appears in the saliva as an antibacterial agent [50]. However, after measuring several additional saliva samples, it was found that thiocyanate is more often NOT observed in saliva as shown in Figure 12A. Although thiocyanate does not spectrally interfere with 5-FU, nor is it likely to interfere with spectra of the 5-FU metabolites or other drugs, it or other anions in saliva, such as phosphates, nitrates or sulfates, could block the SERS-generating metal surfaces. Consequently methods were investigated to remove such anions. 
Figure 10. SER spectral response as a function of 5-FU concentration $(0.01 \mu \mathrm{g} / \mathrm{mL}$ is lowest point). Conditions: $100 \mathrm{~mW}$ of $785 \mathrm{~nm}, 3 \mathrm{~min}$. Error is $\sim 20 \% \mathrm{RSD}, 18 \%$ shown for $1 \mu \mathrm{g} / \mathrm{mL}$.

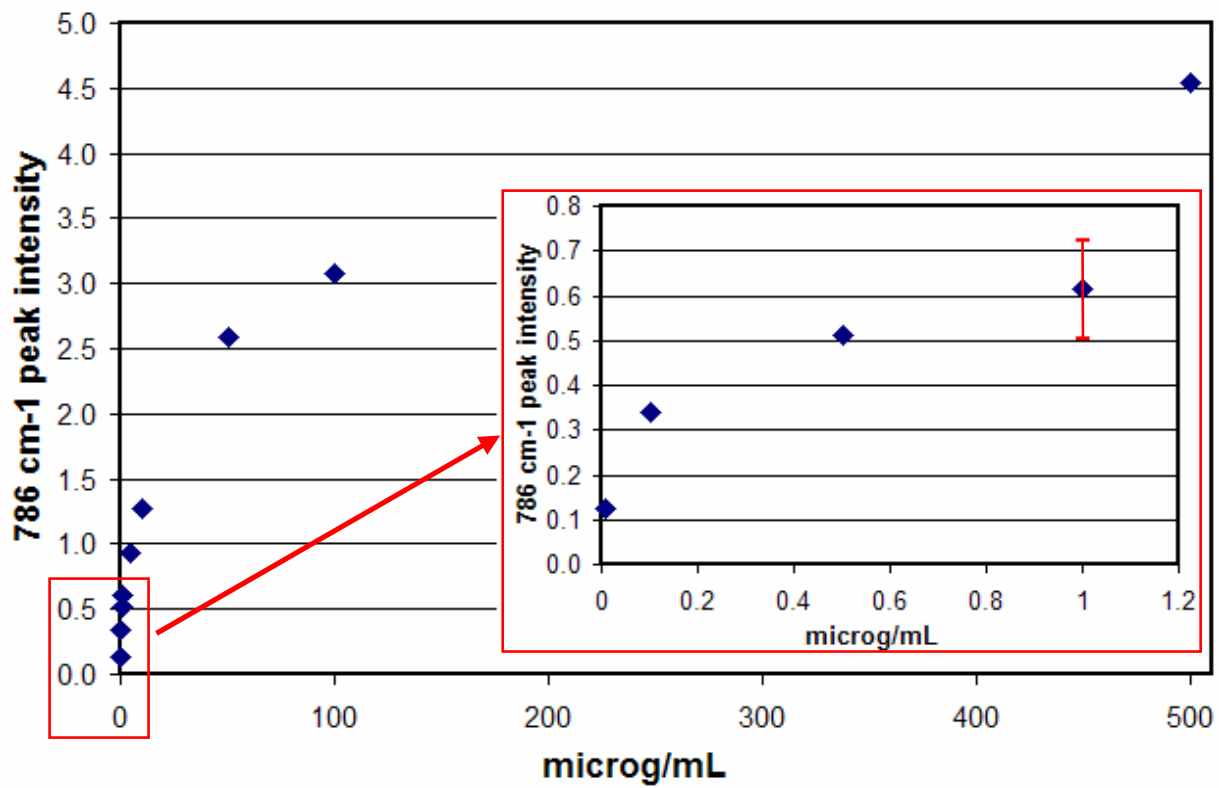

Figure 11. Surface-enhanced Raman spectra of 5FU in A) saliva and B) 1:3 saliva:water. Conditions: $1 \mathrm{mg} / \mathrm{mL}, 100 \mathrm{~mW}$ of $785 \mathrm{~nm}, 1 \mathrm{~min}$. Same initial saliva sample and intensity scale.

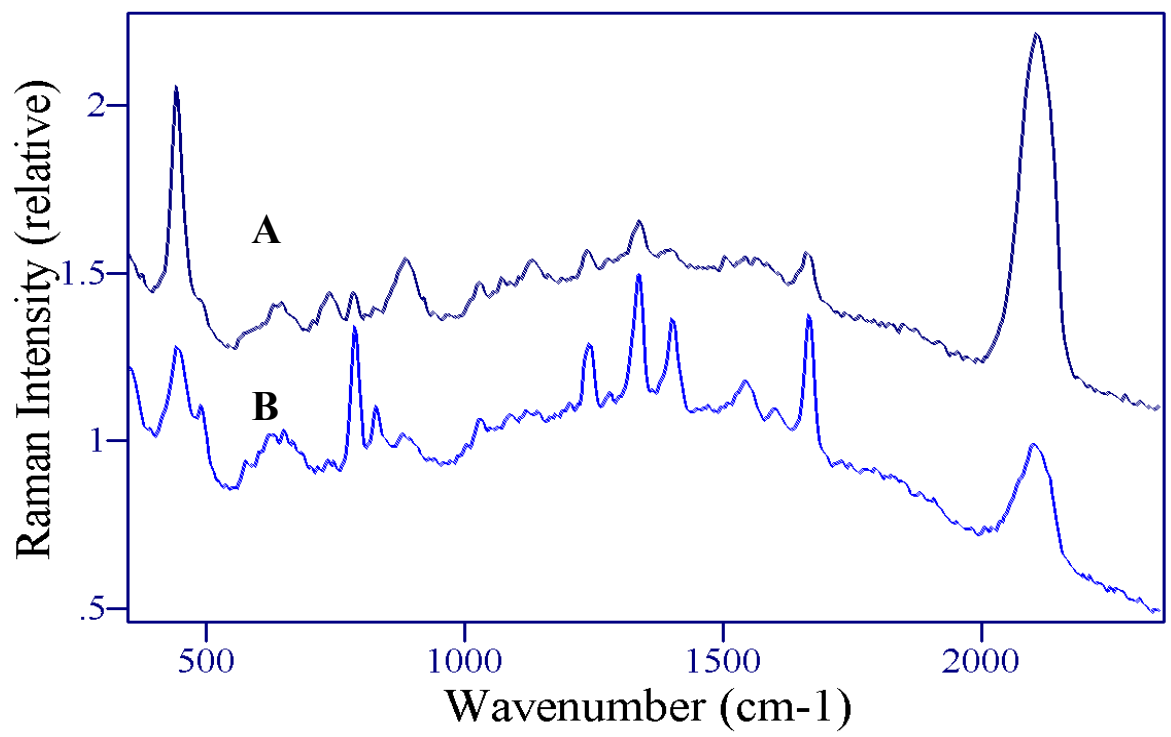


Figure 12. SER spectra of A) saliva-1, B) saliva-2, and C) KSCN. Conditions: $1 \mathrm{mg} / \mathrm{mL}$, $100 \mathrm{~mW}$ of $785 \mathrm{~nm}, 1 \mathrm{~min}$. Note the top spectrum was multiplied by 10 so features could be observed.

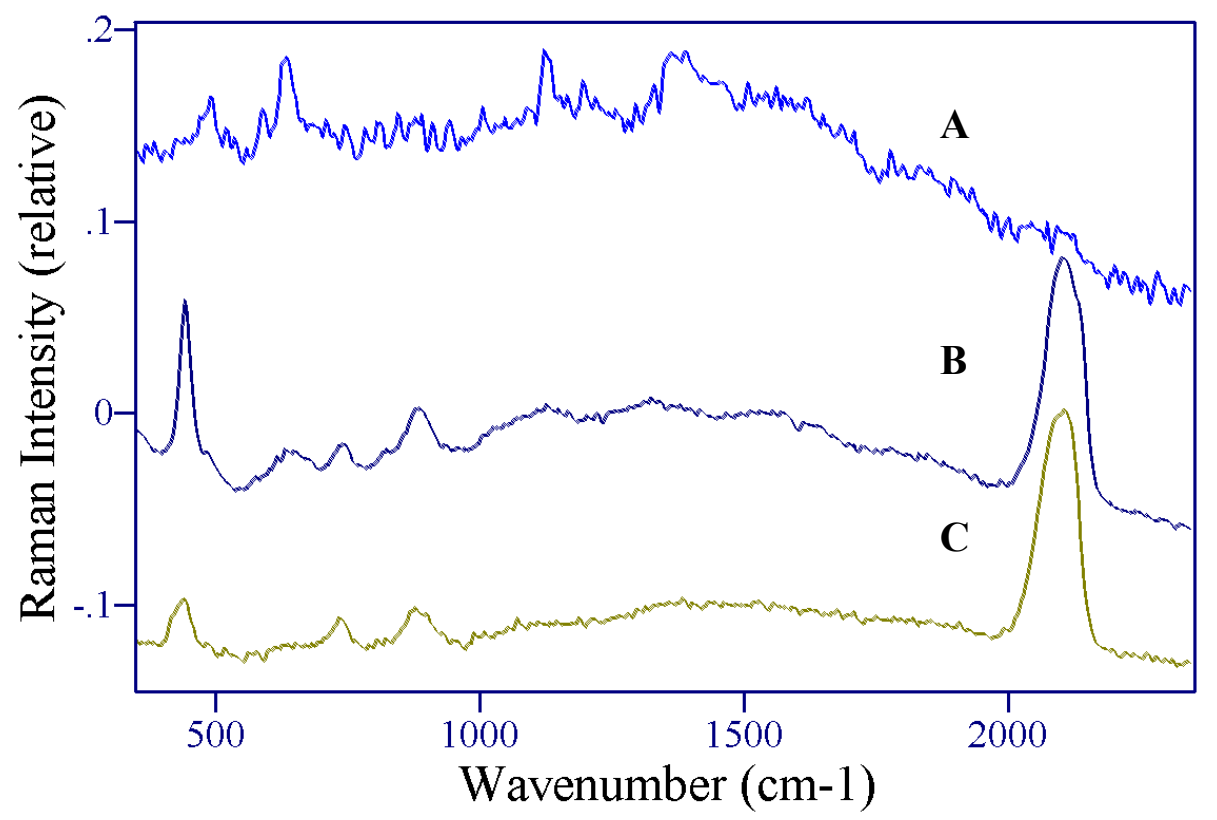

Fortuitously, dilution of the sample with water by a factor of two, intended to solvate 5-FU, but not the large biochemicals of saliva, such as $\alpha$-amylase and mucin, also substantially reduced the thiocyanate signal intensity (Figure 11B). This prompted investigation of $\mathrm{pH}$ as a means to remove anions from the sample solution or exclude them from the silver surface. First, sodium hydroxide was added to the sample so that NaSCN would form and precipitate out of solution. Although this may have worked, a quality SER spectrum of 5-FU was not obtained. Second, the charge on the electropositive silver surface was made negative by treatment with $\mathrm{HCl}$, which produced a $\mathrm{Cl}^{-}$layer to repel anions. This also required acidifying the sample solution so that the 5-FU present would be predominantly neutral and attracted to the silver surface to generate SERS (see Figure 9). Acetic acid produced the desired effect. Figures 13 and 14 shows the results for two different saliva samples to which 50 and $2 \mu \mathrm{g} / \mathrm{ml} 5$-FU were added, respectively. In each case, $1 \mathrm{~mL}$ acetic acid was added to a 1 $\mathrm{mL}$ sample, stirred for 2 minutes, approximately $10 \mu \mathrm{L}$ were drawn into SERS-active capillaries by syringe, that were first treated with $5 \mathrm{mM} \mathrm{HCl}$, and a 1 minute SER spectrum was measured.

The $50 \mu \mathrm{g} / \mathrm{mL} 5$-FU sample produced a quality spectrum (Figure 13, signal-to-noise ratio equaled 72 for the $786 \mathrm{~cm}^{-1}$ peak) with good reproducibility, as shown for three median spectra (Figure 13 inset). A SERS measurement of the same saliva without 5-FU produces a background spectrum, devoid of thiocyanate peaks (Figure 13B). The spectral quality of the $2 \mu \mathrm{g} / \mathrm{mL} 5$-FU sample was considerably lower, as the spectrum was dominated by the glass capillary luminescence (Figurer 14). Nevertheless, subtraction of this background reveals the characteristic 5-FU spectrum, which in this case includes thiocyanate peaks (Figure 14C). The $785 \mathrm{~cm}^{-1}$ peak height for this $\sim 1 \mu \mathrm{g} / \mathrm{mL}$ saliva plus acid sample is approximately the same as the $0.01 \mu \mathrm{g} / \mathrm{mL}$ sample in water. This suggests that as little as $1 / 100^{\text {th }}$ of the 5-FU reaches the silver surface and gets spectrally enhanced. It further suggests that, at least at this concentration, thiocyanate, other ions, proteins or enzymes block the silver surface 
and/or sol-gel pores, reducing sensitivity. Nevertheless, the measured concentration is equivalent to that required to evaluate dosage, and only a $10 \mu \mathrm{L}$ sample $\left(1 / 5^{\text {th }}\right.$ of a drop) was needed. Furthermore, the entire measurement, including acid pretreatment was accomplished in 4 minutes.

Figure 13. SER spectra of 5-FU in $\mathrm{pH}$ adjusted saliva for A) $50 \mu \mathrm{g} / \mathrm{mL} 5$-FU and B) undoped saliva. Inset: 3 repeat measurements. Conditions: $100 \mathrm{~mW}$ of $785 \mathrm{~nm}, 1 \mathrm{~min}$.

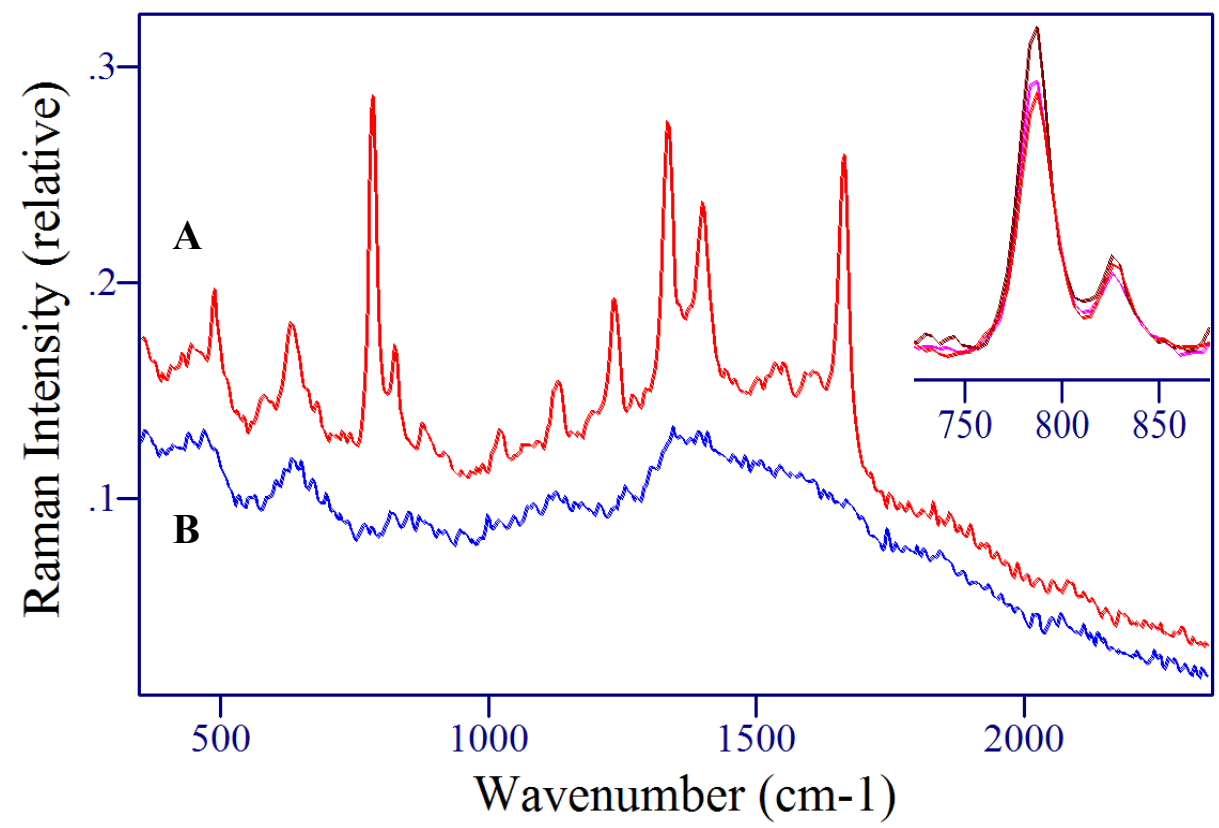

Figure 14. $2 \mu \mathrm{g} / \mathrm{mL}$ 5-FU A) before and C) after subtraction of B) the glass capillary background. Conditions: $\mathrm{HCl}$ washed silver-doped sol-gel capillaries, $100 \mathrm{~mW}$ of $785 \mathrm{~nm}$, $1 \mathrm{~min}$.

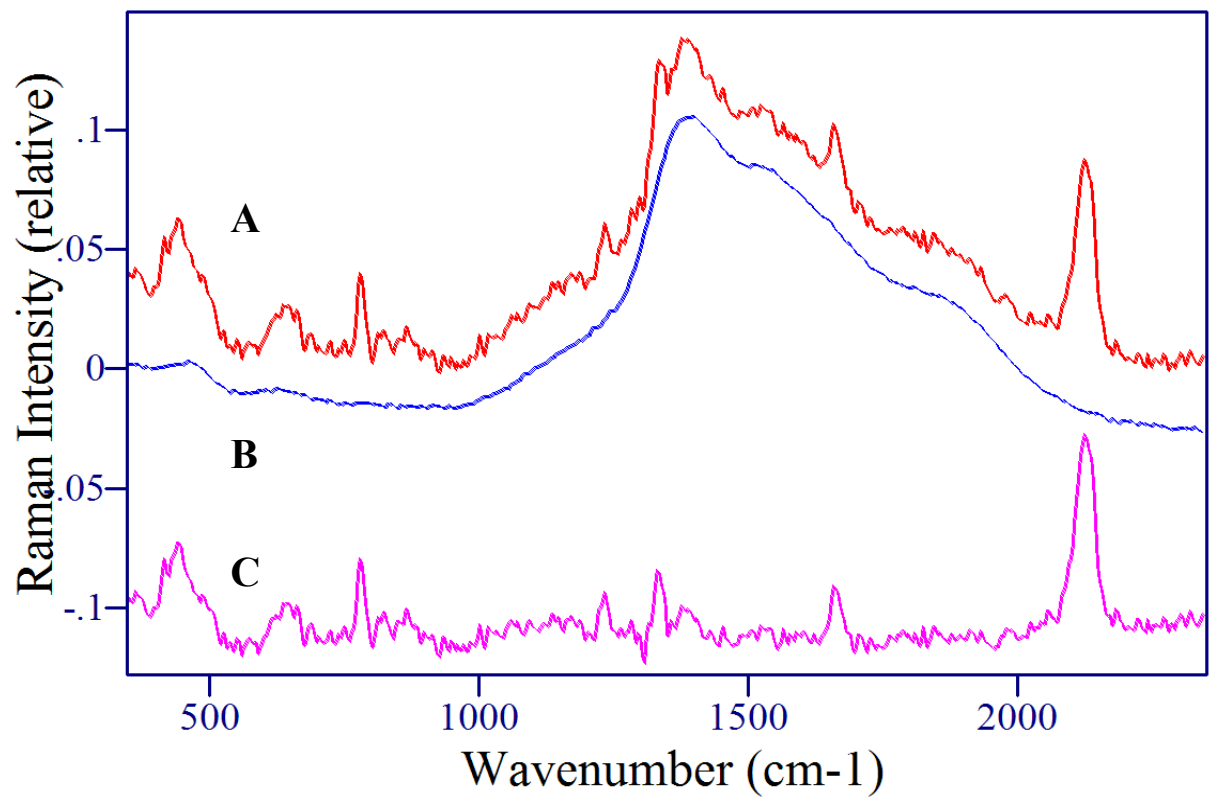




\section{Conclusions}

In this article the surface-enhanced Raman spectral measurements for 5-fluorouracil, 5fluorouridine and 5-fluoro-2'-deoxyuridine are described and tentative vibrational assignments are given. The SER spectra for these drugs were sufficiently different that the parent drug and its metabolites could be uniquely identified by this spectroscopy. Glass capillaries filled with silver-doped sol-gels were used to perform these measurements, as well as those of 5-FU artificially added to saliva. A reasonable signal-to-noise ratio spectrum was obtained for $2 \mu \mathrm{g}$ of 5-FU in $1 \mathrm{~mL}$ saliva, consistent with the expected physiological range of $1-30 \mu \mathrm{g} / \mathrm{mL}$ for this chemotherapy drug. The measurement, including pretreatment with acetic acid and the spectral acquisition, was accomplished in less than 4 minutes. The ability to measure $5-\mathrm{FU}$ at $\mu \mathrm{g} / \mathrm{mL}$ concentrations in less than 5 minutes presented here brings us closer to our goal of developing disposable SERS-active capillaries or lab-on-chip devices that could be used to measure 5-FU and metabolite concentrations in chemotherapy patient saliva and thereby provide metabolic data that would allow regulating dosage on a patient-by-patient basis.

\section{Experimental}

\section{General}

5-Flourouracil (2,4-dihydroxy-5-fluoropyrimidine), 5-fluorouridine, 5-fluoro-2'-deoxyuridine, and leucovorin (N5-formyl-5,6,7,8-tetrahydropteroyl-L-glutamic acid), and all chemicals used to prepare the silver-doped sol-gel coated vials and capillaries were obtained from Sigma-Aldrich (St. Louis, $\mathrm{MO})$ and used without further purification.

\section{Solutions and measurements}

5-FU concentrations from 0.01 to $1,000 \mu \mathrm{g} / \mathrm{mL}$ were prepared in HPLC grade water and 2 to 1,000 $\mu \mathrm{g} / \mathrm{mL}$ in saliva. The saliva used was donated by employees of Real-Time Analyzers, and the $\mathrm{pH}$ was measured at 6.95 to 7.05 , but the exact composition was not determined. For the pH study of 5-FU, a 1 $\mathrm{mg} / \mathrm{mL}$ stock solution was prepared, adjusted to $\mathrm{pH} 3.7$ using $0.1 \mathrm{M} \mathrm{HNO}_{3}$, and then added to a $2 \mathrm{~mL}$ SERS-active vial (Real-Time Analyzers, Simple SERS Sample Vials, Middletown, CT). After the SERS measurement, the $2 \mathrm{~mL}$ solution was returned to the stock solution and made basic using $0.1 \mathrm{M}$ $\mathrm{KOH}$. Prior to re-addition to the same SERS-active vial, the vial was first rinsed three times with distilled water, then twice with the new solution prior to SERS measurement. This procedure was repeated until a $\mathrm{pH}$ of 10.7 was obtained and measured. Then the entire sequence was repeated, but instead $0.1 \mathrm{M} \mathrm{HNO}_{3}$ was used to make the solution incrementally acidic to a final measurement $\mathrm{pH}$ of 3.3. In all, $\mathrm{pH}$ measurements were performed at 3.3, 3.7, 4.3, 4.8, 5.4, 5.6, 6.5, 9.2, and 10.7.

The remaining measurements were performed in SERS-active capillaries. SER-active vials and SER-active capillaries were prepared according to published procedures using a silver precursor and an alkoxide precursor [51-54]. The alkoxide precursors were mixed with silver amine precursor in an $8 / 1 \mathrm{v} / \mathrm{v}$ ratio. In the case of the vials, the silver amine precursor consisted of a $5 / 1 \mathrm{v} / \mathrm{v}$ ratio of $1 \mathrm{~N}$ $\mathrm{AgNO}_{3}$ to $28 \% \mathrm{NH}_{3} \mathrm{OH}$, while the alkoxide precursor consisted of a $2 / 1 \mathrm{v} / \mathrm{v}$ ratio of methanol to 
tetramethyl orthosilicate. Then $140 \mu \mathrm{L}$ were introduced into $2 \mathrm{~mL}$ glass vials, which were then spincoated. In the case of the capillaries, the alkoxide consisted of a $5 / 1 / 1 \mathrm{v} / \mathrm{v} / \mathrm{v}$ ratio of methyltrimethoxysilane, tetramethyl orthosilicate, and octadecyltrimethoxysilane, and $15 \mu \mathrm{L}$ were drawn by syringe into 1-mm diameter glass capillary to coat an $\sim 15 \mathrm{~mm}$ length. In both cases, after sol-gel formation, the incorporated silver ions were reduced with dilute sodium borohydride. However, in the case of the capillaries, they were also rinsed with a $5 \mathrm{mM} \mathrm{HCl}$ solution to provide a negative charged layer and improve the SERS-activity. It has been shown that a layer of negative charge on silver provided by chloride anions can greatly enhance the interaction of some analytes and substantially increase surface-enhanced Raman scattering [55,56]. In fact the SERS of uracil in $0.1 \mathrm{M}$ $\mathrm{KCl}$ obtained on a silver electrode was found to be substantially more intense than uracil obtained on silver embedded in a sol-gel [57].

The sample solutions were either added by pipette into the SERS-active vials or drawn into SERactive capillaries using a syringe. In both cases the vial or capillaries were mounted horizontally on an XY positioning stage (Conix Research, Springfield, OR) such that the focal point of an $\mathrm{f} / 0.7$ aspheric lens was positioned just inside the glass wall. Further details of the apparatus can be found in [36]. The lens focused the beam into the sample and collected the scattered radiation back along the same axis. A dichroic filter (Omega Optical, Brattleborough, VT) was used to reflect the excitation laser to the lens and pass the Raman scattered radiation collected by the lens. An f/2 achromat was used to collimate the laser beam exiting a $200 \mu \mathrm{m}$ core diameter source fiber optic, while a second $\mathrm{f} / 2$ achromat was used to focus the scattered radiation into a $365 \mu \mathrm{m}$ fiber optic (Spectran, Avon, CT). A short pass filter was placed in the excitation beam path to block the silicon Raman scattering generated in the source fiber from reflecting off sampling optics and reaching the detector. A long pass filter was placed in the collection beam path to block the sample Rayleigh scattering from reaching the detector.

An FT-Raman spectrometer (Real-Time Analyzers, model IRA-785, Middletown, CT) equipped with a $785 \mathrm{~nm}$ diode laser and a silicon photo-avalanche detector was used to acquire the surfaceenhanced and normal Raman spectra. The spectrometer was used to deliver 50 to $300 \mathrm{~mW}$ of power at the SERS and Raman samples and generate spectra with $8 \mathrm{~cm}^{-1}$ resolution. Since these capillaries are in the developmental stage, and some non-uniformity in sol-gel structure still exists, each capillary was measured at 9 positions along the length of the capillary with 1-mm spacing, then the three high and three low peak intensity values were discarded and the three middle values averaged to yield the reported spectra. All peak intensities used for calculations were measured peak heights.

\section{Acknowledgements}

The authors are grateful to the late Professor John Murren of Yale University for insightful discussions regarding chemotherapy drugs and his enthusiasm for this program, the late Beth Ordway, whose struggle against cancer initiated this collaboration, and the late Carl Farquharson who helped us realize the challenges of saliva sampling during chemotherapy treatment. This program was funded in part by NIH (1R43CA94457-01). 


\section{References and Notes}

1. Malet-Martino, M.; Martino, R. Clinical studies of three oral prodrugs of 5-fluorouracil. $T$. Oncologist 2002, 1, 288-323.

2. Baker, S. D.; Verweij, J.; Rowinsky, E. K.; Donehower, R. C.; Schellens, J. H.; Grochow, L. B.; Sparreboom, A. Role of body surface area in dosing of investigational anticancer agents in adults, 1991-2001. J. Nat. Cancer Inst. 2002, 94, 1883-1888.

3. Diasio, R. B.; Harris, B. E. Clinical Pharmacology of 5-fluorouracil. Clin. Pharmacokinet. 1989, 16, 215.

4. Malet-Martino, M.; Martino, R. T. Clinical Studies of Three Oral Prodrugs of 5-Fluorouracil (Capecitabine, UFT, S-1): A Review. Oncologist 2002, 7, 288.

5. Casale, F.; Canaparo, R.; Serpe, L.; Muntoni, E.; Pepa, C. D.; Costa, M.; Mairone, L.; Zara, G. P.; Fornari, G.; Eandi, M. Plasma concentrations of 5-fluorouracil and its metabolites in colon cancer patients. Pharmacol. Res. 2004, 50, 173-179.

6. Diasio, R. B.; Beavers, T. L.; Carpenter, J. T. Familial deficiency of dihydropyrimidine dehydrogenase. J. Clin. Invest. 1988, 81, 47-51.

7. Fleming, G. F.; Vokes, E. E.; Buse, J. B.; Mick, R.; Dushay, J.; Levitan, D.; Dolan, M. E. Peripheral blood mononuclear cell dihydropyrimidine dehydrogenase activity in volunteers with and without diabetes mellitus. Cancer Chemother. Pharmacol. 1996, 37, 569-573.

8. Dawling, S.; Essex, E. G.; Ward, N.; Widdop, B. Gas Chromatographic Measurement of Cocaine in Serum, Plasma and Whole Blood. Ann. Clin. Biochem. Sept. 1990, 27, 478-481.

9. Helbock, H. J.; Beckman, K. B.; Shigenaga, M. K.; Walter, P.; Woodall, A. A.; Yeo, H. C.; Ames, B. N. DNA oxidation matters: The HPLC-EC assay of 8-oxo-deoxyguanosine and 8-oxo-guanine. Proc. Natl. Acad. Sci. USA 1998, 95, 288-293.

10. Jankowiak, R.; Small, G. J. Fluorescence Line Narrowing: A High Resolution Window on DNA and Protein Damage from Chemical Carcinogens. (invited article) Chem. Res. Toxicol. 1991, 4, 256.

11. Burton, L. C.; James, C. A. Rapid Method for the Determination of Ifosfamide and Cyclophosphamide in Plasma by High-Performance Liquid Chromatography with Solid-Phase Extraction. J. Chromatogr. 1988, 431, 450-454.

12. McKinney, P. E.; Phillips, S.; Gomez, H. F.; Brent, J.; MacIntyre, M. Vitreous Humor Cocaine and Metabolite Concentrations: Do Postmortem Specimens Reflect Blood Levels at the Time of Death. J. Forensic Sci. Jan. 1995, 40, 102-107.

13. Goodman, M.; Riley, M. B. Chemotherapy: Principles of administration. In Cancer Nursing: Principles and Practice, $4^{\text {th }}$ Ed.; Groenwald, S. L., Frogge, M. H., Goodman, G., Yarbro, C. H. Eds.; Jones and Bartlett: Boston, MA, USA, 1997; pp. 31-386.

14. Cone, E. T.; Jenkins, A. J. Handbook of Analytical Therapeutic Drug Monitoring and Toxicology. Wong, S. H. Y., Sunshine, I., Eds.; CRC Press: New York, USA, 1997; Chapter 18.

15. de Jonge, M. J.; Verwiej, J. V.; Loos, W. J.; Dallaire, B. K.; Sparreboom, A. Clinical pharmacokinetics of encapsulated oral 9-aminocamptothecin in plasma and saliva. Clin. Pharmacol. Ther. 1999, 65, 491-499. 
16. Takahashi, T.; Fujiwara, Y.; Sumiyoshi, H.; Isobe, T.; Yamaoka, N.; Yamakido, M. Salivary drug monitoring of irinotecan and its active metabolite in cancer patients. Cancer Chemothe.r Pharmacol. 1997, 40, 449-52.

17. van Warmerdam, L. J.; van Tellingen, O.; ten Bokkel Huinink, W. W.; Rodenhuis, S.; Maes, R. A.; Bijnen, J. H. Monitoring carboplatin concentrations in saliva: a replacement for plasma ultrafiltrate measurements? Ther. Drug Monit. 1995, 17:5, 465-470.

18. Joulia, J. M.; Pinguet, F.; Ychou, M.; Duffour, J.; Astre, C.; Bressolle, F. Plasma and salivary pharmacokinetics of 5-fluorouracil (5FU) in patients with metastatic colorectal cancer receiving 5FU bolus plus continuous infusion with high-dose folinic acid. Eur. J. Cancer 1999, 35:2, 296301.

19. Chamberlain, J. The Analysis of Drugs in Biological Fluids, $2^{\text {nd }}$ Ed.; CRC Press: France, 1995.

20. Kneipp, K.; Wang, Y.; Dasari, R. R.; Feld, M. S. Approach to Single-Molecule Detection Using Surface-Enhanced Resonance Raman Scattering (SERRS): A Study Using Rhodamine 6G on Colloidal Silver. Appl. Spectrosc. 1995, 49, 780-784.

21. Nie, S.; Emory, S. R. Probing Single Molecules and Single Nanoparticles by Surface-Enhanced Raman Scattering. Science 1997, 275, 1102.

22. Garrel, R. L. Surface-Enhanced Raman Spectroscopy. Anal. Chem. 1989, 61, 401A-411A.

23. Storey, J. M. E.; Barber, T. E.; Shelton, R. D.; Wachter, E. A.; Carron, K. T.; Jiang, Y. Applications of Surface-Enhanced Raman Scattering (SERS) to Chemical Detection. Spectroscopy 1995, 10, 20-25.

24. Sutherland, W. S.; Laserna, J. J.; Angebranndt, M. J.; Winefordner, J. D. Surface-Enhanced Raman Analysis of Sulfa Drugs on Colloidal Silver Dispersion. Anal. Chem. 1990, 62, 689-693.

25. Carter, J. C.; Brewer, W. E.; Angel, S. M. Raman spectroscopy for the in situ identification of cocaine and selected adulterants. Appl. Spectrosc. 2000, 54, 1876-1881.

26. Perez, R.; Ruperez, A.; Laserna, J. J. Evaluation of silver substrates for surface-enhanced Raman detection of drugs banned in sport practices. Anal. Chim. Acta 1998, 3, 76(2):255.

27. Cîntă Pînzaru, S.; Pavel, I.; Leopold, N.; Kiefer, W. Identification and characterization of pharmaceuticals using Raman and surface-enhanced Raman Scattering. J. Raman Spectrosc. 2004, 35, 338-346.

28. Nabiev, I. R.; Morjani, H.; Manfait, M. Selective analysis of antitumor drug interaction with living cells as probed by surface-enhanced Raman spectroscopy. Eur. Biophys. J. 1991, 19, 311316.

29. Beljebbar, A.; Sockalingum, G.; Morjani, H.; Manfait, M. Raman and SERS micro-spectroscopy on living cells: a promising tool towards cellular-drug response and medical diagnosis. Proc. SPIE 1999, 3608, 175-184.

30. Nabiev, I.; Baranov, A.; Chourpa, I.; Beljebbar, A.; Sockalingum, G.; Manfait, M. Does Adsorption on the Surface of Silver Colloid Perturb Drug/DNA Interactions? Comparative SERS, FT-SERS, and Resonance Raman Study of Mitoxantrone and Its Derivatives. J. Phys. Chem. 1995, 99, 1608-1613.

31. Rivas, L.; Murza, A.; Sanchez-Cortes, S.; Garcia-Ramos, J. V. Adsorption of acridine drugs on silver: surface-enhanced resonance Raman evidence of the existence of different adsorption sites. Vib. Spectros. 2001, 25, 19-28. 
32. Fabriciova, G.; Sanchez-Cortez, S.; Garcia-Ramos, J. V.; Miskovsky, P. Joint application of micro-Raman and surface-enhanced Raman spectroscopy to the interaction study of the antitumoral anthraquinone drugs danthron and quinzarin with albumins. J Raman Spectrosc. 2004, 35, 384-389.

33. Gift, A. D.; Shende, C.; Inscore, F. E.; Maksymiuk, P.; Farquharson, S. Five minute analysis of chemotherapy drugs and metabolites in saliva: Evaluating Dosage. Proc. SPIE 2004, 5261, 135141.

34. Farquharson, S.; Shende, C.; Inscore, F. E.; Maksymiuk, P.; Gift, A. D. Analysis of 5-fluorouracil in saliva using surface-enhanced Raman spectroscopy. J. Raman Spectrosc. 2005, 36, 208-212.

35. Gift, A. D.; Shende, C.; Inscore, F. E.; Farquharson, S. Analysis of the chemotherapy drug 5fluorouracil and its metabolites by surface-enhanced Raman spectroscopy. Proc. SPIE 2005, 5588, 70-77.

36. Farquharson, S.; Gift, A.; Shende, C.; Maksymiuk, P.; Inscore, F; Murren, J. Detection of 5fluorouracil in saliva using surface-enhanced Raman spectroscopy. Vib. Spectrosc. 2005, 38, 7984.

37. Lord, R. C.; Thomas, G. J. Jr. Raman spectral studies of nucleic acids and related molecules - I Ribonucleic acid derivatives. Spectrochim. Acta 1967, 23A, 2551-2591.

38. Tsuboi, M.; Takahashi, S.; Harada, I. Infrared and Raman spectra of nucleic acids-vibrations in the base residues. In Physico-chemial properties of nucleic acids; Academic Press: New York, USA, 1973; Vol. 2, pp. 91-145.

39. Rastogi V. K.; Mital H. P.; Sharma. S. N. Laser Raman and IR Spectra of 5-Fluorouracil. XIth International Conference on Raman Spectroscopy, London, UK, 1988.

40. Rastogi, V. K.; Jain, V.; Yadav, R. A.; Singh, C.; Palafox, M. A. Fourier transform Raman spectrum and $a b$ initio and density functional computations of the vibrational spectrum, molecular geometry, atomic charges and some molecular properties of anticarcinogenic drug 5-fluorouracil. J. Raman Spectrosc. 2000, 31, 595-603.

41. Otto, C.; van den Tureel, T. J. J.; de Mul, F. F. M.; Greve, J. Surface-enhanced Raman spectroscopy of DNA bases. J. Raman Spectrosc. 1986, 17, 289-298.

42. Torres, E.; Winefordner, J. D. Trace determination of nitrogen-containing drugs by surface enhanced raman scattering spectrometry on silver colloids. Anal. Chem. 1987, 59, 1626-1632.

43. Suh, J. S.; Moskovits, M. Surface-Enhanced Raman Spectroscopy of amino acids and nucleotide bases adsorbed on silver. J. Am. Chem. Soc. 1986, 108, 4711-4718.

44. Farquharson, S.; Lay, P. A.; Weaver, M. J. Surface-Enhanced Raman Spectroscopy of Pentaammineosmium (III)/(II) and Petaammineruthenium (II) Containing Pyridine, Pyrazine or 4,4'-Bipyridine Ligands at Silver Electrodes: Vibrational Assignments. Spectrochim. Acta 1984, 40A, 907-921.

45. Farquharson, S.; Gift, A.; Shende, C.; Inscore, F.; Murren, J. Detection of chemotherapy drugs in saliva by surface-enhanced Raman spectroscopy. In Applications of Surface-Enhanced Raman Spectroscopy. Farquharson, S., Ed.; CRC Press: Boca Raton, FL, accepted.

46. Carmona, P.; Rodriguez-Casado, A.; Molina, M.; Escobar, R. Raman Spectroscopic study of uridine nucleotides: Structural information and conformational features. J. Raman Spectrosc. 1999, 30, 631-636. 
47. Jang, Y. H.; Sowers, L. C.; Gagin, T.; Goddard, W. A. III; First Principles calculation of pKa Values for 5-Substituted Uracils. J. Phys. Chem. A 2001, 105, 274-280.

48. Farquharson, S.; Gift, A.; Maksymiuk, P.; Inscore, F.; Smith W. pH dependence of methyl phosphonic acid, dipicolinic acid, and cyanide by surface-enhanced Raman spectroscopy. Proc. SPIE 2004, 5269, 117-125.

49. Tadayyoni, M. A., Farquharson, S.; Li, T. T. -T.; Weaver, M. J. Surface-Enhanced Raman Spectroscopy of Electrochemically Characterized Interfaces. Transition-Metal Isothiocyanate Adsorbates at Silver Electrodes. J. Phys. Chem. 1984, 88, 4701-4706.

50. Ermans, A. M.; Delange, F.; Van Der Velden, M.; Kinthaert, J. Possible role of cyanide and thiocyanate in the etiology of endemic cretinism. In Human Development and the Thyroid Gland. Relation to Endemic Cretinism; Stanbury, J. B.; Kroc, R. L. Eds.; Plenum Press: New York, USA, 1972; p. 455.

51. Farquharson, S.; Maksymiuk, P. Simultaneous chemical separation and surface-enhancement Raman spectral detection using silver-doped sol-gels. Appl. Spectrosc. 2003, 57, 479-482.

52. Farquharson, S.; Lee, Y. H.; Nelson, C. Material for SERS and SERS sensors and method for preparing the same. U.S. Pat. 6,623,977, 2003.

53. Farquharson, S.; Maksymiuk, P. Simultaneous chemical separation and surface-enhanced Raman spectral detection using metal-doped sol-gels. U.S. Pat. 6,943,031, 2005.

54. Farquharson, S.; Maksymiuk, P. Chemical separation and plural point, surface-enhanced Raman spectral detection using metal-doped sol-gels. U.S. Pat. 6,943,032, 2005.

55. Jeanmaire, D. L.; van Duyne, R. P. Surface Raman Spectroelectrochemistry. J. Electroanal. Chem. 1977, 84, 1-20.

56. Dou, X.; Jung, Y. M.; Cao, X-Q.; Ozaki, Y. Surface-Enhanced Raman Scattering of Biological Molecules on Metal Colloid II. Appl. Spectrosc. 1999, 53, 1440.

57. Farquharson, S.; Smith, W. W.; Lee, Y. H.; Elliott, S.; Sperry, J. F. Detection of biological signatures: A comparison of electrolytic and metal-doped sol-gel surface-enhanced Raman media. Proc. SPIE 2002, 4575, 62-72.

Sample Availability: All samples used in this study are commercially available (e.g. Sigma-Aldrich). Contact the corresponding author regarding SERS sample systems.

(C) 2008 by the authors; licensee Molecular Diversity Preservation International, Basel, Switzerland. This article is an open-access article distributed under the terms and conditions of the Creative Commons Attribution license (http://creativecommons.org/licenses/by/3.0/). 